\title{
BMJ Open Income support programmes for the older adults in South Asia: a scoping review protocol
}

\author{
Eti Rajwar, ${ }^{1}$ Prachi Pundir, ${ }^{1}$ Shradha S Parsekar (D) , ${ }^{1}$ \\ Bhumika Tumkur Venkatesh (1) , ${ }^{1}$ Tobias Vogt (i) ${ }^{2,3}$
}

To cite: Rajwar E, Pundir P, Parsekar SS, et al. Income support programmes for the older adults in South Asia: a scoping review protocol. BMJ Open 2021;11:e050676. doi:10.1136/ bmjopen-2021-050676

- Prepublication history and additional supplemental material for this paper are available online. To view these files, please visit the journal online (http://dx.doi.org/10.1136/ bmjopen-2021-050676).

Received 25 February 2021 Accepted 22 July 2021

\section{Check for updates}

(C) Author(s) (or their employer(s)) 2021. Re-use permitted under CC BY-NC. No commercial re-use. See rights and permissions. Published by BMJ.

${ }^{1}$ Public Health Evidence South Asia, Prasanna School of Public Health, Manipal Academy of Higher Education, Manipal, Karnataka, India

${ }^{2}$ Faculty of Spatial Science, Population Research Centre, University of Groningen, Groningen, The Netherlands ${ }^{3}$ Health Demography Research Group, Prasanna School of Public Health, Manipal Academy of Higher Education, Manipal, Karnataka, India

Correspondence to

Dr Tobias Vogt; t.c.vogt@rug.nl

\section{ABSTRACT}

Introduction South Asian countries are ageing and experiencing a rapid increase in proportion of the older population. Income support programmes are of central importance for the older adults as they may help to mitigate the poverty risks associated with ageing and losing the ability to generate income from labour. Evidence related to the income support programmes can help in understanding whether the programmes have been impactful. This scoping review will map the evidence (and gaps) related to income support programmes and create a base to identify the feasibility of future primary research and/or the scope of systematic reviews in the areas where evidence is available.

Methods and analysis The Joanna Briggs Institute scoping review methodology will be followed. Eligibility criteria for the scoping review will be based on the 'PCC' or the 'Population-Concept-Context' concept. Advanced search for the relevant articles will be conducted in MEDLINE (via PubMed), Embase, Scopus, Campbell Collaboration, 3ie International Initiative for Impact Evaluation and Web of Science. Additional resources search will be conducted in important organisational websites. Findings of the scoping review will be summarised using descriptive information (frequencies and percentages) for the available evidence on concept (ie, income support programmes), population characteristics and other study variables.

Ethics and dissemination The review is based on data from available literature, hence an ethical approval is not necessary. With this review, we attempt to provide recommendations to the research community and the policymakers about the currently available evidence and the research required for income support of older adults in South Asia, so that resources can be directed towards addressing the same. We plan to disseminate the findings through presentation in international conference and publication in a peer-reviewed journal.

Review registration Not registered.

\section{INTRODUCTION}

Population ageing or relative increase of older age groups in a population is a phenomenon experienced in almost all countries around the world. In 2019, there were around 703 million people above the age of 65 years living around the globe. This number

\section{Strengths and limitations of this study}

This scoping review will follow the Joanna Briggs Institute's methods and will undertake comprehensive database and additional resources search, for example, searching organisational websites and reference checking of the included studies.

- Considering the language limitation to English and difficulty in accessing some of the unpublished documents, there may be possibility of missing some publications.

- There may be heterogeneity in definition of older adults or retirement age and income support programmes, which may affect drawing common conclusion.

is estimated to increase to 1.5 billion by $2050 .^{1}$ The percentage of people above age 65 years has increased from $6 \%$ in the year 1990 to $9 \%$ in 2019 and is projected to increase to $16 \%$ by 2050. According to the United Nations (UN) report, four regions of the world including Central and South Asia will witness a doubling of the older population by $2050 .{ }^{1}$

Population ageing is accompanied by various concerns, ranging from the sustainability of statutory healthcare and pension systems over fiscal imbalances, to declining labour force participation and economic productivity. At the core of these concerns are the rising average life spans and the potential decline in physical health and cognitive functioning with increased age. In South Asia, the life expectancy at birth has risen from 37.4 years in the early 1950 s to 71.2 years in $2015-$ 2020 and is expected to increase by 6 more years by $2050 .^{1}$ In the period 2015-2020, a 65-year-old South Asian could expect to live on an average of 15.4 more years. ${ }^{1}$ This gain in life years was accompanied by a rise in noncommunicable disease (NCD) prevalence that substantially contributed to the years lived with disability among the older population. $^{23}$ In 2019, NCDs accounted for $81 \%$ 
Box 1 Enhanced scoping review framework (Peters et al) $)^{21}$

Defining and aligning the objectives/questions.

- Developing and aligning the inclusion criteria with the objectives and questions.

- Describing the planned approach to evidence searching and selection.

- Searching for the evidence.

- Selecting the evidence.

- Extracting the evidence.

Charting the evidence.

- Summarising the evidence in relation to the different objectives and questions.

- Consultation of the information scientists or experts (this process should be considered throughout).

of the years lived with disabilities among the South Asian population aged $65-89$ years. ${ }^{4}$

The gain in years of life in combination with an increase in NCD prevalence become particularly challenging for the older adults, who lose their capacity to generate income and rely on the support of others, over longer periods of their lives. Low income and general income insecurity are the most common challenges experienced by the older people in South Asia, often associated with poverty and social exclusion. In these low/middle-income countries (LMICs), the poverty risk is especially prevalent as many older adults cannot rely on public support, but require private savings or family support to cover their needs. ${ }^{5}$ In South Asian countries like India, the middle generation provides financial and in-kind support for their older parents, and at the same time for their dependent children. In case of limited resources and extended

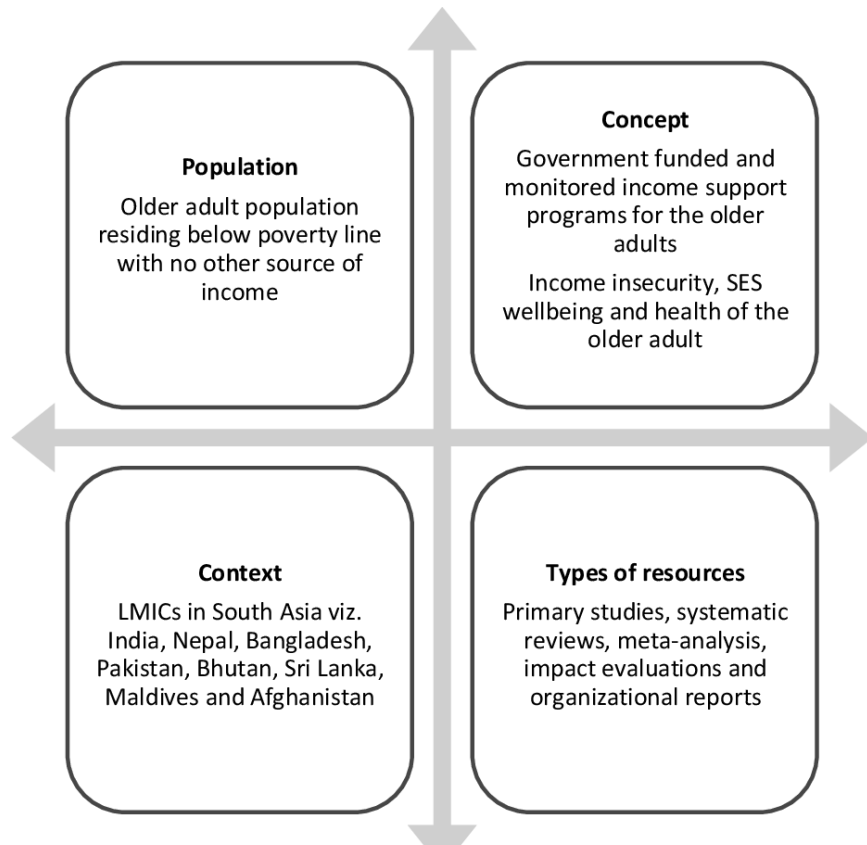

Figure 1 Eligibility criteria. LMICs, low/middle-income countries; SES, socioeconomic status. periods of need, the older adults may also witness a relative decline of family support. ${ }^{6}$

Lack of enabling environment with regard to infrastructure, that is, absence of friendly homes for older adults and transportation facilities, is one of the most common and ignored (in countries like India) challenges faced by older adults in their daily lives. ${ }^{7}$ The needs and challenges of the older adults vary according to their age, literacy level, socioeconomic status, health, living conditions and other contextual factors. ${ }^{8}$ Living arrangements like joint family systems in India define problems faced by the older adults as at post-retirement, they become dependent on the economic capacity of the family unit. In such systems, the family and community become a source of informal financial and social support for the older adults. ${ }^{8}$ Nevertheless, there are older adults in India who are living alone or with their partner. With the increasing trend of smaller family size, especially in the urban areas, older adults choose to (or are forced to) live on their own. ${ }^{9}$ Income support schemes play an important role in all of the above arrangements, by providing financial independence to the older adults.

The poverty risk also has a strong gender component, as older women in South Asia are economically dependent on their spouses or other male relatives. This dependency arises from substantially lower labour force participation, ${ }^{10}$ lower educational attainment, ${ }^{11}$ longer life expectancy and more years spent in poor health. ${ }^{12}$ Hence, women are particularly vulnerable and in need of family support as their abilities to generate savings from labour are limited and they are lacking public support for old age. Apart from gender, the old age poverty risks are also determined by the socioeconomic position over the life course. ${ }^{13}$ Despite major improvements in the last decade, social exclusion, and economic and health inequalities remain important obstacles to avoid poverty at older ages. ${ }^{14} 15$ According to the UN's Human Development Report, South Asian countries still face high inequalities in education, income or job security. ${ }^{16}$ With a steadily increasing life expectancy in South Asia, the number of dependent older people will exert pressure on the available resources and general economic condition of their families.

Income support programmes or pension schemes are of central importance for the older adults and their families, as these programmes may help to mitigate the age-related poverty risks of losing the ability to generate income from labour. In the Sustainable Development Goals (SDGs) adopted by all UN member states, (taxfunded) income support provision for the older adults is explicitly mentioned as a target to reduce poverty (SDG 1 ). They also acknowledge the poverty risk of families with dependent older family members and the need for assistance of families to prevent poverty. SDG 5 highlights the need for social pensions for older women, as a measure of improving women's status in the family and community, and to give them greater decision-making autonomy. ${ }^{17}$ 


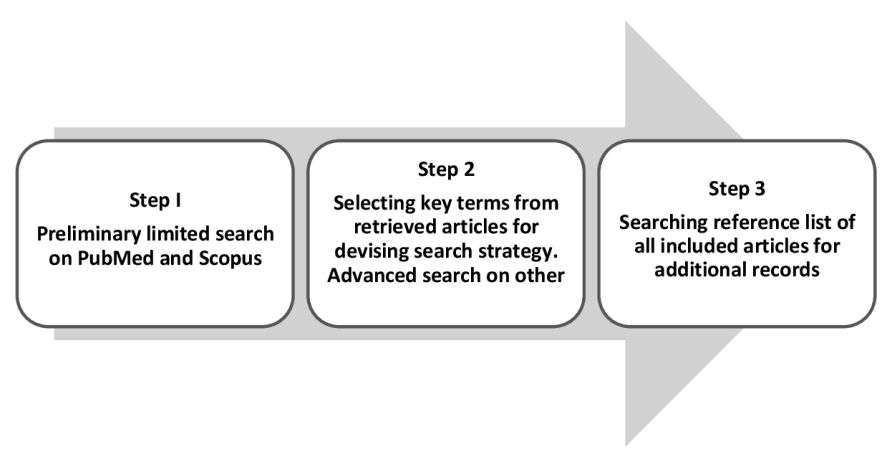

Figure 2 Three-step searching process for scoping review.

South Asian governments have announced income support schemes for older adults to tackle the problem of income insecurity. Programmes like National Social Assistance Program, Indira Gandhi National Old Age Pension Scheme, Senior Citizen Savings Schemes, Pradhan Mantri Vyaya Vandana Yojana and Varishtha Pension Bima Yojana are some of the schemes proposed by the Indian government to help older adults. Programmes in other South Asian countries are Old Age Allowances, Nepal (introduced by the government in 1994), for all citizens of $60+$ years who are not entitled to contributory pensions ${ }^{18}$; allowances for widow, destitute and deserted women, Bangladesh, introduced in 2010 by the World Bank $^{19}$; and the Elderly Assistance Programme, Sri Lanka, which is a cash transfer programme introduced by the government for citizens aged $70+$ years, without any other income. ${ }^{20}$

Evidence related to the implementation and impact of these income support programmes is needed to understand whether these programmes have been successful or require modifications for improvement, and to understand the reach/coverage of these programmes. This can be used for informing policymakers if they made progress in achieving the SDGs or if alterations in the schemes are required. This scoping review proposes mapping the evidence related to the older adults' income support programmes, including the type of evidence available, gender-specific benefits proposed by the income support programmes and the related gaps in the available research knowledge. To date, a scoping review in this domain has not been conducted in South Asia, therefore, our review will create a base to identify the feasibility of future primary research and/or the scope of systematic reviews in the areas where the evidence is available. The aim of this scoping review is to map evidence related to income support programmes for older adults in South Asia.

We will define and align the following research questions: (a) What are the different income support programmes for older adults in South Asia?; (b) What is the type of evidence available on the impact of these income support programmes on the lives of the older adults living in these regions?; (c) What are the gaps in the research related to older adult income support programmes in South Asia?
METHODS AND ANALYSIS

\section{Protocol design}

We will follow the Joanna Briggs Institute (JBI) scoping review methodology ${ }^{21}$ devised using Arksey and O'Malley framework $^{22}$ and Levac et al framework ${ }^{23}$; which was further modified by Peters et al..$^{21}$ The different stages under this methodology are as follows: (a) defining and aligning the objectives or questions; (b) defining and aligning inclusion criteria with the objectives and questions; (c) describing the planned approach to evidence searching and selection; (d) searching for the evidence; (e) selecting the evidence; (f) extracting the evidence; (g) charting the evidence; (h) summarising the evidence in relation to the different objectives and questions; (i) consultation of the information scientists or experts. Box 1 presents the scoping review framework after enhancements by Peters et al. ${ }^{21}$ Protocol amendments, if any, will be documented with justification in the final review.

\section{Inclusion and exclusion criteria}

The eligibility criteria for the scoping review will be based on the 'PCG' or the 'Population-Concept-Context' concept and will include the types of resources component, as presented in figure 1.

\section{Population}

Older population above 60 years of age (as 60 years is the age when people on average retire in South Asia), residing in South Asia. Both citizens and refugees will be included. People availing benefits from any other schemes (other than the defined income support programmes that do not qualify under any of the pillars mentioned in the operational definition below) and retired government employees receiving regular pension will not be included.

\section{Concept}

The main concept for this scoping review is the income support programmes or the financial support programmes for the older adults, also known as the old age pension programmes. Income support programmes operational in South Asia and qualifying under the five pillars described below will be included. Evidence related to the impact of these programmes on the income security of the older adults, socioeconomic status, well-being and health status of the older adults will be charted.

Income support programmes are one of the programmes for the older adults or the pension system that reduce the risk associated with ageing. ${ }^{24}$ According to the World Bank, income support programmes consist of certain elements that have specific characteristics to increase individual and societal benefit and reduce risks. Such income support programmes are called multipillar income support programmes with five basic pillars: (1) zero pillar or non-contributory pillar, this is social pension that provides minimal level of prevention; (2) first pillar or the contributory system that is related to earning and replaces a certain part of income; (3) second 


\begin{tabular}{|c|c|c|}
\hline SI no & Details & Information \\
\hline 1 & Bibliographical details & Author, year of publication, publisher details \\
\hline 3 & Geographical location & Country of origin, location \\
\hline 6 & Outcome & Impact of the income support programme on income security, health status \\
\hline 7 & $\begin{array}{l}\text { Other findings relevant to the review } \\
\text { question }\end{array}$ & Type of evidence, gaps in research knowledge, research priority areas \\
\hline
\end{tabular}

pillar which is mandatory and which means the personal savings account; (4) third pillar which is voluntary, the form can be individual, employer sponsored, and is flexible and discretionary in nature; (5) fourth pillar that is intergenerational or intrafamily support to the older adults, in form or financial or non-financial support. ${ }^{24} \mathrm{We}$ will use the above-mentioned definition and components or multipillar programme for defining and identifying the income support programmes in this scoping review.

Context

The setting for this scoping review will be the low-resource setting LMICs in the South Asian region, that is, India, Pakistan, Bhutan, Nepal, Bangladesh, Sri Lanka, Afghanistan and Maldives. The studies conducted among South Asians living in other countries will not be considered.

\section{Types of resources}

For this scoping review, we will consider the available resources that give information on the income support programmes, for example, primary studies, systematic reviews, meta-analysis, impact evaluations and organisational reports. We will not consider opinion articles, editorials and letters.

\section{Search strategy}

Search will be based on JBI's three-step methodology of searching for scoping reviews. In the first step, a preliminary limited search will be conducted in MEDLINE (via PubMed) and Scopus. The retrieved papers will then be checked and the relevant text terms (in the title and abstract of the papers) and the index/key terms mentioned in the retrieved articles will be used to build a search strategy for searching in all other relevant databases such as MEDLINE (via PubMed), Embase, Scopus, Campbell Collaboration, 3ie International Initiative for Impact Evaluation and Web of Science; this will be the second step of the searching process. Search strategy to be used for searching in PubMed is given in online supplemental file 1 . In the third step, the reference list of all the identified articles will be searched for additional studies. Authors of the studies/reports will be contacted, in case more information is needed on any article. Englishlanguage articles published in the last 20 years will be included. Organisational websites will be searched for additional information and reports related to the income support programmes. The three-step searching process is depicted in figure 2.

\section{Selection of sources of evidence and data management}

Selection of the sources or articles, that is, screening of studies, will be independently performed by the reviewers. Disagreements on study exclusion will be resolved via consensus or by the third reviewer. Selection of the studies or screening will be based on the eligibility criteria, that is, the PCC concept and will be conducted in two stages: the title/abstract screening stage and the full-text screening stage. The titles and abstracts will be screened as per the eligibility criteria, the ones that qualify will be included for full-text screening and the rest will be excluded with documented reasons. The final included articles after full-text screening will be available for data extraction. The entire selection process will be reported using the Preferred Reporting Items for Systematic Reviews and Meta-Analyses flow chart. Data will be managed with the help of EndNote V.X7 referencing software and Microsoft Excel spreadsheets.

\section{Extraction of results}

Extraction or charting of the data will be done independently, to provide a logical and descriptive summary of the results, which will be in alignment with the objective of the scoping review. The extraction of results will be done by using a charting table that will consist of bibliographical details such as author details and year of publication; study details such as objectives of the study and country of origin; population characteristics; methodology of the study; details about the income support programme and the impact of income support programme; findings relevant to the review question, etc. The charting table will be modified during the review stage and will be updated based on the data. Charting of the studies will be an iterative process where the chart table will be continuously updated. Preliminary charting format is given in table 1.

\section{Data analysis}

This scoping review will provide descriptive information (frequencies and percentages) for the available evidence 
Table 2 Information about income support programmes for older adults in South Asia

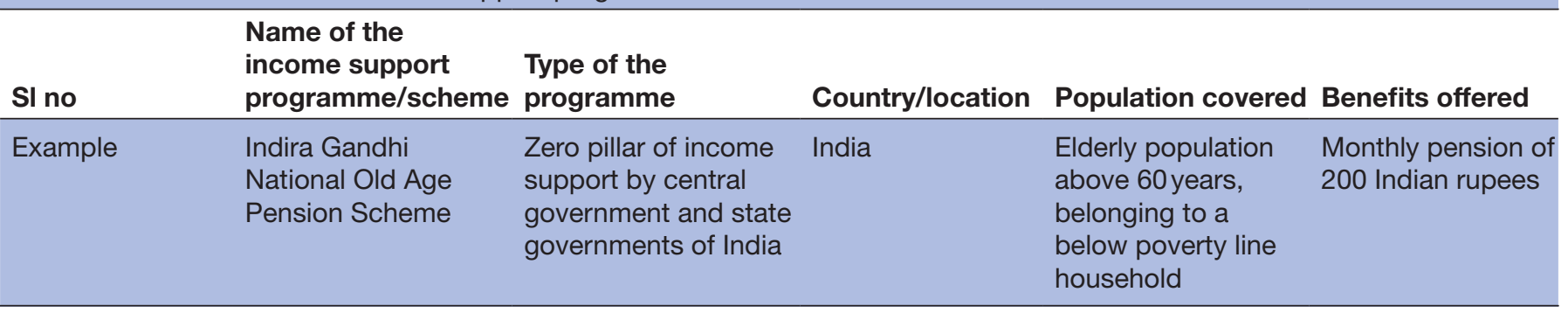

on concept and population, that is, income support programmes and for population characteristics and for other data variables reported in the Extraction of results section. As this is a scoping review, we will not perform quality assessment of the included studies. Additionally, we will not perform sensitivity analysis, subgroup analysis or meta-regression and will not report publication bias. As we are only mapping the evidence available for income support programmes in South Asia, and not synthesising the findings, therefore, we will not perform Grading of Recommendations, Assessment, Development and Evaluations for assessing the certainty or strength of the body of synthesised evidence

\section{Presentation of results}

The results of the scoping review will be presented in a tabular form. Results for the different types of older adults' income support programmes will be presented in a table that will give information about the (a) name of the income support programme; (b) type of the income support programme; (c) country or location; (d) population covered and (e) benefits offered, as presented in table 2.

The evidence on income support programmes will be mapped according to the following categories: (a) intervention type; (b) study population; (c) outcome of the intervention; (d) country/location; (e) type of evidence (research method); (f) gaps in the research. This is presented in table 2 . The contents of this table are based on preliminary understanding of the topic and will be modified based on the data and findings of the scoping review. For the final presentation, this map will be colour coded according to the different categories and subcategories. Table 3 is supported by a hypothetical example, for the purpose of readers' understanding (design and content of the table with respect to the mapped variables can be modified after completing the data extraction).

\section{Patient and public involvement}

We did not involve patients or the public while designing this protocol.

\section{ETHICS AND DISSEMINATION}

To the best of our knowledge, this scoping review is based on a novel concept, to gather the evidence on income support programmes for older adults in South Asia. The review does not require ethical approval, because it is based on the literature that is already available. The findings from this scoping review will be used to advise

Table 3 Map for the available evidence

\begin{tabular}{|c|c|c|c|c|c|c|}
\hline \multirow[b]{3}{*}{ Study ID } & \multicolumn{6}{|l|}{ Categories } \\
\hline & $\begin{array}{l}\text { Intervention } \\
\text { name and type } \\
\end{array}$ & $\begin{array}{l}\text { Study } \\
\text { population }\end{array}$ & Outcome & $\begin{array}{l}\text { Country/ } \\
\text { location }\end{array}$ & Type of evidence & Gaps \\
\hline & $\begin{array}{l}\text { Name and } \\
\text { type of income } \\
\text { support } \\
\text { programme }\end{array}$ & $\begin{array}{l}\text { Older adult, } \\
\text { dependent, } \\
\text { widow/ } \\
\text { widower, } \\
\text { separated, age }\end{array}$ & $\begin{array}{l}\text { Income security, } \\
\text { well-being, SES } \\
\text { status, health }\end{array}$ & $\begin{array}{l}\text { Country, } \\
\text { rural/urban } \\
\text { setting }\end{array}$ & $\begin{array}{l}\text { Primary research, } \\
\text { SR, meta-analysis }\end{array}$ & $\begin{array}{l}\text { Gaps in research } \\
\text { knowledge or } \\
\text { evidence }\end{array}$ \\
\hline Xyz (example) & $\begin{array}{l}\text { Indira Gandhi } \\
\text { National Old } \\
\text { Age Pension } \\
\text { Scheme-central } \\
\text { government- } \\
\text { funded income } \\
\text { support } \\
\text { programme }\end{array}$ & $\begin{array}{l}\text { Older adults } \\
\text { above } 60 \text { years } \\
\text { (including } \\
\text { destitute, } \\
\text { widow), from } \\
\text { below poverty } \\
\text { line household }\end{array}$ & $\begin{array}{l}\text { Household } \\
\text { expenditure, } \\
\text { social security, } \\
\text { poverty status, } \\
\text { health indicators }\end{array}$ & India & $\begin{array}{l}\text { Primary research } \\
\text { via one-time cross- } \\
\text { sectional survey }\end{array}$ & $\begin{array}{l}\text { Not able to } \\
\text { estimate } \\
\text { effectiveness or } \\
\text { impact of the } \\
\text { programme due } \\
\text { to study design } \\
\text { limitations }\end{array}$ \\
\hline
\end{tabular}

SES, socioeconomic status; SR, systematic review. 
the research community and the policymakers about the existing available evidence and the research required for income support of older adults in South Asia, so that the resources can be directed towards addressing the same. We plan to disseminate the findings through presentation in international conference and publication in a widely accessible peer-reviewed journal.

\section{Twitter Prachi Pundir @prachipundir and Shradha S Parsekar @ParsekarShrads}

Acknowledgements The authors would like to thank Public Health Evidence South Asia, Prasanna School of Public Health, Manipal Academy of Higher Education, Manipal and Population Research Centre, Faculty of Spatial Sciences and University of Groningen for providing the logistic support.

Contributors TV conceptualised the topic and will be the guarantor of the review. BTV, ER, PP, SSP and TV contributed to formulation of the research questions. ER conceived the idea of the scoping review and contributed extensively to the methods, drafting and editing of the manuscript. BTV, PP, SSP and TV contributed to drafting and editing of the manuscript. All the authors reviewed the protocol and have approved the final manuscript.

Funding The authors have not declared a specific grant for this research from any funding agency in the public, commercial or not-for-profit sectors.

Competing interests None declared.

Patient consent for publication Not required.

Provenance and peer review Not commissioned; externally peer reviewed.

Supplemental material This content has been supplied by the author(s). It has not been vetted by BMJ Publishing Group Limited (BMJ) and may not have been peer-reviewed. Any opinions or recommendations discussed are solely those of the author(s) and are not endorsed by BMJ. BMJ disclaims all liability and responsibility arising from any reliance placed on the content. Where the content includes any translated material, BMJ does not warrant the accuracy and reliability of the translations (including but not limited to local regulations, clinical guidelines, terminology, drug names and drug dosages), and is not responsible for any error and/or omissions arising from translation and adaptation or otherwise.

Open access This is an open access article distributed in accordance with the Creative Commons Attribution Non Commercial (CC BY-NC 4.0) license, which permits others to distribute, remix, adapt, build upon this work non-commercially, and license their derivative works on different terms, provided the original work is properly cited, appropriate credit is given, any changes made indicated, and the use is non-commercial. See: http://creativecommons.org/licenses/by-nc/4.0/.

\section{ORCID iDs}

Shradha S Parsekar http://orcid.org/0000-0002-8824-9198

Bhumika Tumkur Venkatesh http://orcid.org/0000-0002-3338-6478

Tobias Vogt http://orcid.org/0000-0002-1962-3473

\section{REFERENCES}

1 World Population Ageing, 2019. Available: https://www.un.org/en/ development/desa/population/publications/pdf/ageing/WorldPopulat ionAgeing2019-Highlights.pdf [Accessed 15 Jan 2021].

2 Ghaffar A, Reddy KS, Singhi M. Burden of non-communicable diseases in South Asia. BMJ 2004;328:807-10.

3 Siegel KR, Patel SA, Ali MK. Non-Communicable diseases in South Asia: contemporary perspectives. Br Med Bull 2014;111:31-44.

4 Global Burden of Disease Results Tool | GHDx [Internet]. Available: http://ghdx.healthdata.org/gbd-results-tool [Accessed 15 Jan 2021].

5 Lee R, Mason A. Aging in Asia: Findings from New and Emerging Data Initiatives [Internet]. Washington, DC: The National Academics Press, 2012.
6 Vogt T, Kluge F, Lee R. Intergenerational resource sharing and mortality in a global perspective. Proc Natl Acad Sci U S A 2020;117:22793-9.

7 Ageing in the Twenty-First Century [Internet]. Available: /publications/ ageing-twenty-first-century [Accessed 15 Jan 2021].

8 Raju SS. Studies on ageing in India: a review, 2014. Available: https://doi.org/10.1017/CBO9781139683456.009

9 Finanacial status of older people in India - An assessemnt [Internet]. New Delhi: Agewell Research \& Advocacy Centre, n.d. Available: https://social.un.org/ageing-working-group/documents/seventh/ AgewellFoundationSubmission.pdf [Accessed 25 Jan 2021].

10 Chaudhary R, Verick S. Female labour force participation in India and beyond [Internet]. International Labour Organization; 2014. (ILO Working Papers). Report No.: 994867893402676 . Available: https:// ideas.repec.org/p/ilo/ilowps/994867893402676.html [Accessed 15 Jan 2021].

11 Lutz W, Goujon KC A A, Stonawski M. Demographic and human capital scenarios for the 21st century [Internet]. Luxembourg: European Commission, Joint Research Centre. (2018 assessment for 201 countries), 2018: 598. https://ec.europa.eu/jrc/sites/jrcsh/files/ lutz_et_al_2018_demographic_and_human_capital.pdf

12 WHO. Global Health Observatory data repository | By category | Life expectancy and Healthy life expectancy - Data by country [Internet]. WHO. Available: https://apps.who.int/gho/data/node.main.688?lang= en [Accessed 15 Jan 2021].

13 O'Rand AM. Nine - Stratification and the Life Course: Life Course Capital, Life Course Risks, and Social Inequality. In: Binstock RH, George LK, Cutler SJ, et al, eds. Handbook of Aging and the Social Sciences (Sixth Edition) [Internet]. Burlington: Academic Press, 2006: 145-62. http://www.sciencedirect.com/science/article/pii/ B9780120883882500122

14 Reducing poverty by tackling social exclusion: a DFID policy paper, 2005. Available: https://www2.ohchr.org/english/issues/ development/docs/socialexclusion.pdf [Accessed 15 Jan 2021].

15 Health inequalities in old age. Available: https://www.un.org/ development/desa/ageing/wp-content/uploads/sites/24/2018/04/ Health-Inequalities-in-Old-Age.pdf [Accessed 15 Jan 2021].

16 Human Development Data Center | Human Development Reports [Internet]. Available: http://hdr.undp.org/en/data [Accessed 25 Jan 2021].

17 Sustainable Development Goals [Internet]. UNDP. Available: https:// www.undp.org/content/undp/en/home/sustainable-developmentgoals.html [Accessed 25 Jan 2021].

18 Sony K, Upreti BR, Paudel SB. The Old Age Allowance and perceptions of the state in Rolpa District, Nepal [Internet]. Secure Livelihoods Research Consortium; 2014 Oct p. 1-22. (Researching livelihoods and services affected by conflict). Report No.: 25 . Available: https://securelivelihoods.org/wp-content/uploads/TheOld-Age-Allowance-and-perceptions-of-the-state-in-Rolpa-DistrictNepal.pdf

19 Social Safety Nets in Bangladesh Help Reduce Poverty and Improve Human Capital [Internet]. World Bank. Available: https://www. worldbank.org/en/news/feature/2019/04/29/social-safety-netsin-bangladesh-help-reduce-poverty-and-improve-human-capital [Accessed 15 Jan 2021]

20 Tilakaratna G. Income security for older persons in Sri Lanka. Available: https://www.unescap.org/sites/default/d8files/Session3 Income\%20Security\%20for\%20OIder\%20Persons\%20in\%20Sri\% 20Lanka_Ganga\%20Tilakaratna.pdf [Accessed 15 Jan 2021].

21 Peters MDJ, Godfrey CM, Khalil H, et al. Guidance for conducting systematic scoping reviews. Int J Evid Based Healthc 2015;13:141-6.

22 Arksey H, O'Malley L. Scoping studies: towards a methodological framework. Int J Soc Res Methodol 2005;8:19-32.

23 Levac D, Colquhoun H, O'Brien KK. Scoping studies: advancing the methodology. Implement Sci 2010;5:69.

24 Holzmann R, Hinz R. Old-Age Income Support in the 21st Century: An International Perspective on Pension Systems and Reform [Internet]. The World Bank, 2005. http://elibrary.worldbank.org/doi/ book/ 